\title{
Continuous monitoring of plant sodium transport dynamics using clinical PET
}

\author{
Gihan P. Ruwanpathirana ${ }^{1,2+}$, Darren C. Plett ${ }^{3 \dagger}$, Robert C. Williams ${ }^{1}$, Catherine E. Davey ${ }^{1,2}$, Leigh A. Johnston ${ }^{1,2^{*}}$ (D) \\ and Herbert J. Kronzucker ${ }^{4,5}$
}

\begin{abstract}
Background: The absorption, translocation, accumulation and excretion of substances are fundamental processes in all organisms including plants, and have been successfully studied using radiotracers labelled with ${ }^{11} \mathrm{C},{ }^{13} \mathrm{~N},{ }^{14} \mathrm{C}$ and ${ }^{22} \mathrm{Na}$ since 1939 . Sodium is one of the most damaging ions to the growth and productivity of crops. Due to the significance of understanding sodium transport in plants, a significant number of studies have been carried out to examine sodium influx, compartmentation, and efflux using ${ }^{22} \mathrm{Na}-$ or ${ }^{24} \mathrm{Na}$-labeled salts. Notably, however, most of these studies employed destructive methods, which has limited our understanding of sodium flux and distribution characteristics in real time, in live plants. Positron emission tomography (PET) has been used successfully in medical research and diagnosis for decades. Due to its ability to visualise and assess physiological and metabolic function, PET imaging has also begun to be employed in plant research. Here, we report the use of a clinical PET scanner with a ${ }^{22} \mathrm{Na}$ tracer to examine ${ }^{22} \mathrm{Na}$-influx dynamics in barley plants (Hordeum vulgare L. spp. Vulgare_cultivar Bass) under variable nutrient levels, alterations in the day/night light cycle, and the presence of sodium channel inhibitors.
\end{abstract}

Results: 3D dynamic PET images of whole plants show readily visible ${ }^{22} \mathrm{Na}$ translocation from roots to shoots in each examined plant, with rates influenced by both nutrient status and channel inhibition. PET images show that plants cultivated in low-nutrient media transport more ${ }^{22} \mathrm{Na}$ than plants cultivated in high-nutrient media, and that ${ }^{22} \mathrm{Na}$ uptake is suppressed in the presence of a cation-channel inhibitor. A distinct diurnal pattern of ${ }^{22} \mathrm{Na}$ influx was discernible in curves displaying rates of change of relative radioactivity. Plants were found to absorb more ${ }^{22} \mathrm{Na}$ during the light period, and anticipate the change in the light/dark cycle by adjusting the sodium influx rate downward in the dark period, an effect not previously described experimentally.

Conclusions: We demonstrate the utility of clinical PET/CT scanners for real-time monitoring of the temporal dynamics of sodium transport in plants. The effects of nutrient deprivation and of ion channel inhibition on sodium influx into barley plants are shown in two proof-of-concept experiments, along with the first-ever 3D-imaging of the light and dark sodium uptake cycles in plants. This method carries significant potential for plant biology research and, in particular, in the context of genetic and treatment effects on sodium acquisition and toxicity in plants.

Keywords: Positron emission tomography, Barley, ${ }^{22} \mathrm{Na}$ transport dynamics, Inhibitor effect, Nutrient effect, Diurnal transport

*Correspondence: I.johnston@unimelb.edu.au

${ }^{\dagger}$ Gihan P. Ruwanpathirana and Darren C. Plett contributed equally to this work and are joint first-authors

${ }^{1}$ Melbourne Brain Centre Imaging Unit, The University of Melbourne, Melbourne, VIC, Australia

Full list of author information is available at the end of the article

\section{Background}

The absorption, translocation, accumulation and excretion of substances are fundamental processes in plant physiology that have been successfully studied using radiotracer technologies, for their inherent sensitivity and quantitative accuracy [1-4]. These include methods that

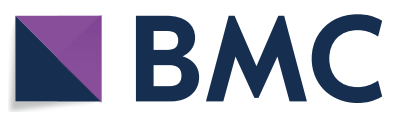

(c) The Author(s) 2021. This article is licensed under a Creative Commons Attribution 4.0 International License, which permits use, sharing, adaptation, distribution and reproduction in any medium or format, as long as you give appropriate credit to the original author(s) and the source, provide a link to the Creative Commons licence, and indicate if changes were made. The images or other third party material in this article are included in the article's Creative Commons licence, unless indicated otherwise in a credit line to the material. If material is not included in the article's Creative Commons licence and your intended use is not permitted by statutory regulation or exceeds the permitted use, you will need to obtain permission directly from the copyright holder. To view a copy of this licence, visit http://creativeco mmons.org/licenses/by/4.0/. The Creative Commons Public Domain Dedication waiver (http://creativecommons.org/publicdomain/ zero/1.0/) applies to the data made available in this article, unless otherwise stated in a credit line to the data. 
employ short-lived radiotracers, labelled with ${ }^{11} \mathrm{C}$ and ${ }^{13} \mathrm{~N}$, for real-time tracing, and long-lived radiotracers, labeled with ${ }^{14} \mathrm{C}$ or ${ }^{22} \mathrm{Na}$, for measuring the accumulation of substances [5].

Nearly 80 years ago, Ruben et al. [6] conducted the first plant study using a short-lived radioisotope ${ }^{11} \mathrm{C}$, to examine photosynthesis. Since then, many studies have been carried out using ${ }^{11} \mathrm{C}$ to study photosynthesis and the carbohydrate source-sink relationship in plants. In addition to ${ }^{11} \mathrm{C}$, radioisotope ${ }^{13} \mathrm{~N}$ is used to study nutrient absorption and transportation characteristics under various conditions $[7,8]$.

One of the most damaging ions to crop growth and productivity, at levels encountered in agricultural soils, is sodium $[9,10]$. Due to the significance of understanding sodium influx characteristics, several studies have been conducted using ${ }^{22} \mathrm{Na}$ radioisotope [11-13], with some also employing ${ }^{24} \mathrm{Na}$ to study both influx and efflux processes [14-16]. Nevo et al. [17] studied the variation of ${ }^{22} \mathrm{Na}$ uptake in wild Emmer wheat in the context of salt tolerance. Smitharani et al. [18] showed that ${ }^{22} \mathrm{Na}$ uptake is significantly lower in salt-tolerant groundnut varieties than in salt-sensitive ones. Notably, however, these studies employed destructive methods to determine radioactivity in plant organs after plant harvesting, not permitting the real-time monitoring of tracer distribution in the living plant.

With the development of high-throughput phenotyping platforms, non-destructive imaging techniques, including visual imaging, thermal infrared imaging, fluorescence imaging, and tomographic imaging, are being employed to analyse plants traits related to the growth, yield and adaptation to biotic and abiotic stress [19]. De Vylder et al. [20] developed a visible light image analysis platform to evaluate plant-shoot phenotypes, while Zia et al. [21] used infrared thermal imaging to identify water-stress tolerant maize genotypes. Windt et al. [22] used a dedicated Magnetic Resonance Imaging (MRI) scanner to compare phloem and xylem flow characteristics and dynamics in poplar, castor bean, tomato, and tobacco. Perret et al. [23] developed a protocol to visualize and quantify roots using computed tomography $(\mathrm{CT})$ and tested it using chickpea plants.

Positron emission tomography (PET) imaging is a non-invasive imaging modality that records radiotracer pathways. It has been successfully used for decades by medical diagnostic and pharmaceutical industries due to its ability to assess physiological and metabolic function in the living, intact organism in real time. McKay et al. [24] were the first to describe the use of PET systems in plant research, studying the long-distance transport in plants by monitoring the movement of ${ }^{18} \mathrm{~F}$ through a separated soybean shoot. Since then, PET systems have been in sporadic use in plant research, to quantitatively assess the uptake, inter-organ transport, and storage of radio-labeled substances [25]. Recently, Converse et al. [2] used an animal PET imaging system to model and experimentally evaluate the uptake of atmospheric fluoride in plants by administrating ${ }^{18} \mathrm{~F}$ to the petioles of Brassica oleracea. De Schepper et al. [26] and Thorpe et al. [27] used ${ }^{11} \mathrm{C}$-labeled PET radiotracers to study ${ }^{11} \mathrm{C}$ transport dynamics in oak phloem tissue and the long-distance transport of the phytohormone methyl jasmonate in tobacco plants, respectively. Recognising the importance of PET in plant research, a dedicated plant PET system, PlanTIS, was developed by Beer et al. [28]. Jahnke et al. [29] used PlanTIS to investigate the allocation of carbon to various plant organs by administering a ${ }^{11} \mathrm{C}$-labeled tracer into beet, radish, and maize plants. Streun et al. [30] developed a second plant-dedicated PET system, phenoPET, but its practical usage remains a work in progress.

There has been one study to date demonstrating the feasibility of clinical PET scanners for plant research, that of Karve et al. [31], in which a Siemens HR + PET scanner was used to quantitatively study C-photoassimilate transport dynamics and allocation patterns in sorghum plants, across vegetative and reproductive stages, by administrating ${ }^{11} \mathrm{CO}_{2}$ to the plants. Although they optimised the scanner settings, 3-D data acquisition and attenuation and scatter correction using transmission scans, to maximise the quantitative accuracy, these scanner corrections, attenuation, scatter and decay corrections, are less accurate compared to correction methods such as CT based attenuation corrections in new clinical PET scanners.

There have been two studies to date of sodium influx in intact plants using PET imaging with a ${ }^{22} \mathrm{Na}$-labeled tracer. Fujimaki et al. [32] determined the translocation directions and rates of sodium ion in a salt-tolerant plant, common reed, and a salt-sensitive plant, rice, under high salt conditions using a positron-emitting tracer planar imaging system. They found absorption of ${ }^{22} \mathrm{Na}$ in the common reed roots, but no transportation to the shoot, and detected ${ }^{22} \mathrm{Na}$ movement from the basal part of the roots to the distal part in the chase step. In contrast, ${ }^{22} \mathrm{Na}$ absorbed in rice was continuously transported and accumulated in the shoot. This study was limited by the planar PET system with limited angular resolution, providing only $2 \mathrm{D}$ images. Further, plants were exposed to a continuous light source, thus effects of photosynthetic activity and transpiration on sodium influx could not be accounted for, and, as well, the initial sodium influx of the experimental plants was not observed. Recently, Ariño-Estrada et al. [33] studied the potential of using a small animal PET scanner to understand different 
sodium-tolerant properties in plant varieties by quantitatively differentiating the sodium transport dynamics between them. In this experiment, 24 green foxtail plants, 12 plants from each of two genotypes, were incubated in a ${ }^{22} \mathrm{Na}^{+}$-containing radioactive growth medium for 14 days and scanned at five time points. Consistent transport dynamics were observed within plants of the same variety and differences between genotypes, which proved the potential of preclinical PET scanners in high-throughput phenotyping of sodium ion transport. Although the initial sodium influx was determined, temporal dynamics were not acquired continuously, nor were diurnal changes of sodium influx examined.

In contrast to the previous studies utilizing animal PET and specialized plant PET scanners, we here demonstrate the utility of clinical PET/CT for plant imaging, by scanning plants continuously for up to 3 days. To the best of our knowledge, this is the first demonstration of imaging plants using a clinical PET scanner with CT based attenuation correction, which is advantageous for better radioactivity quantification in studying plant physiology and CT-based delineation of plant regions of interest (ROIs). In comparison to small PET scanners and specialised plant PET scanners, the large field-of-view (FOV) of clinical PET/CT scanners is beneficial in studying ion dynamics in larger plants. Our work demonstrates the sensitivity of PET-measured ${ }^{22} \mathrm{Na}$-uptake dynamics in plants when sodium influx rates are modified under variable nutrient provisions and the addition of ion channel inhibitors, while providing day/night light cycles consistent with the growth protocols of plants and maintained for the duration of the PET experiments.

\section{Results}

Dynamic PET images of the whole plants, for example from Experiment 2 (Fig. 1), indicated clear ${ }^{22} \mathrm{Na}$ uptake and translocation from the roots to the shoots in each plant grouping with levels influenced both by nutrient status and the presence/absence of $\mathrm{BaCl}_{2}$. Time-lapse 3D-image sequences of radioactivity dynamics for both experiments are provided in Additional files 1 and 2. The analysis of activity over time in each plant condition was remarkably consistent between the experiments for both leaves and roots (Figs. 2, 3, 4 and 5), showing the robustness of the experimental protocol. Due to the influx of ${ }^{22} \mathrm{Na}$, the relative radioactivity in the roots decreased while it increased in the leaves.

Figure 2 shows the nutrient effect on ${ }^{22} \mathrm{Na}$ uptake in plants without $\mathrm{BaCl}_{2}$ and, as expected, low-nutrient plants absorb ${ }^{22} \mathrm{Na}$ at higher rates than the high-nutrient plants. Figure 3 captures the dynamic behaviour of ${ }^{22} \mathrm{Na}$ uptake in plants with $\mathrm{BaCl}_{2}$, demonstrating that

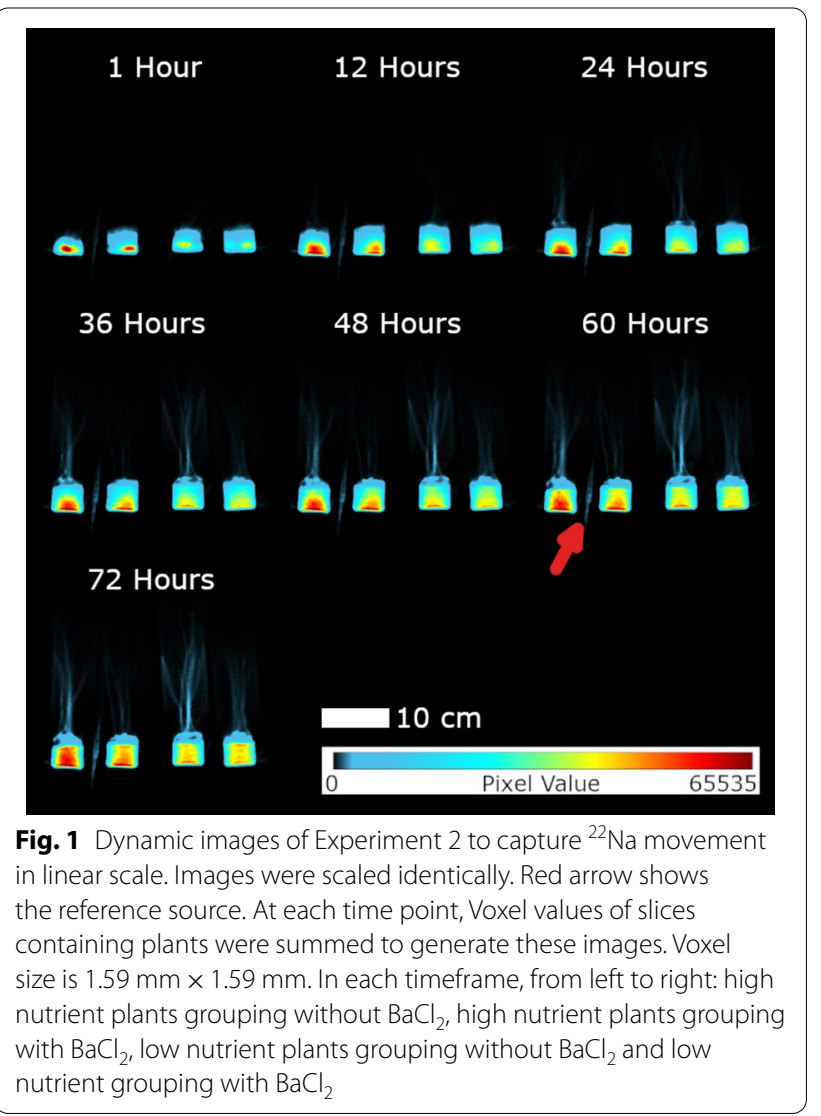

low-nutrient plants transport more ${ }^{22} \mathrm{Na}$ than high-nutrient plants.

Figures 4 and 5, which are rearrangements of Figs. 2 and 3 , illustrate the effect of $\mathrm{BaCl}_{2}$ on ${ }^{22} \mathrm{Na}$ uptake in low-nutrient and high-nutrients plants, respectively. In both instances, plants without $\mathrm{BaCl}_{2}$ show greater ${ }^{22} \mathrm{Na}$ uptake.

As per the figures, there is no significant difference between two comparison plant groups at the beginning of the experiments; with time, the difference become noticeable, and treatments clearly diverge over time. Moreover, there is a discernible diurnal pattern of ${ }^{22} \mathrm{Na}$ influx in all rate of change of relative radioactivity curves where plants absorb significantly more ${ }^{22} \mathrm{Na}$ during the light period, and appear to anticipate the change in light provision by adjusting the ${ }^{22} \mathrm{Na}$-uptake rate to a significantly decreased rate in the dark.

At the end of Experiment 1, radioactivity values in each plant grouping, after the transportation of ${ }^{22} \mathrm{Na}$ to the shoot, were calculated using PET images with and without CT based Attenuation Correction. Since ${ }^{22} \mathrm{Na}$ is a radioisotope with a half-life of 2.605 years, true radioactivity in each plant grouping will be approximately equal to the administered dose, that we consider the ground 


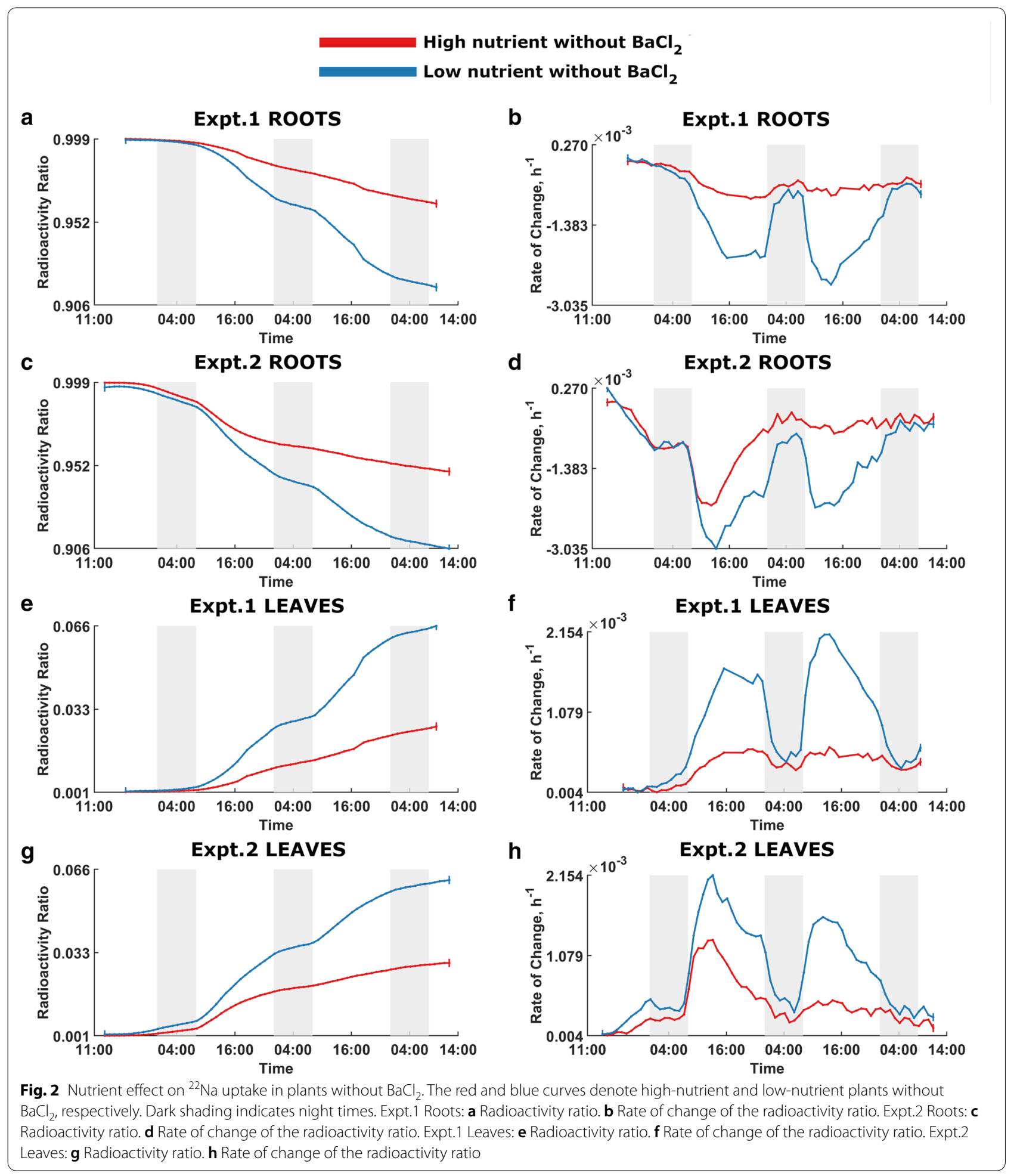

truth total radioactivity values. Table 1 shows that radioactivity values estimated using CT-based Attenuation Correction of the raw PET data are consistently slight overestimates of ground truth. In contrast, radioactivity values were strikingly underestimated without CT-base Attenuation Correction. Figure 6 provides an exemplar image slice reconstructed with and without Attenuation Correction, clearly demonstrating its utility. 


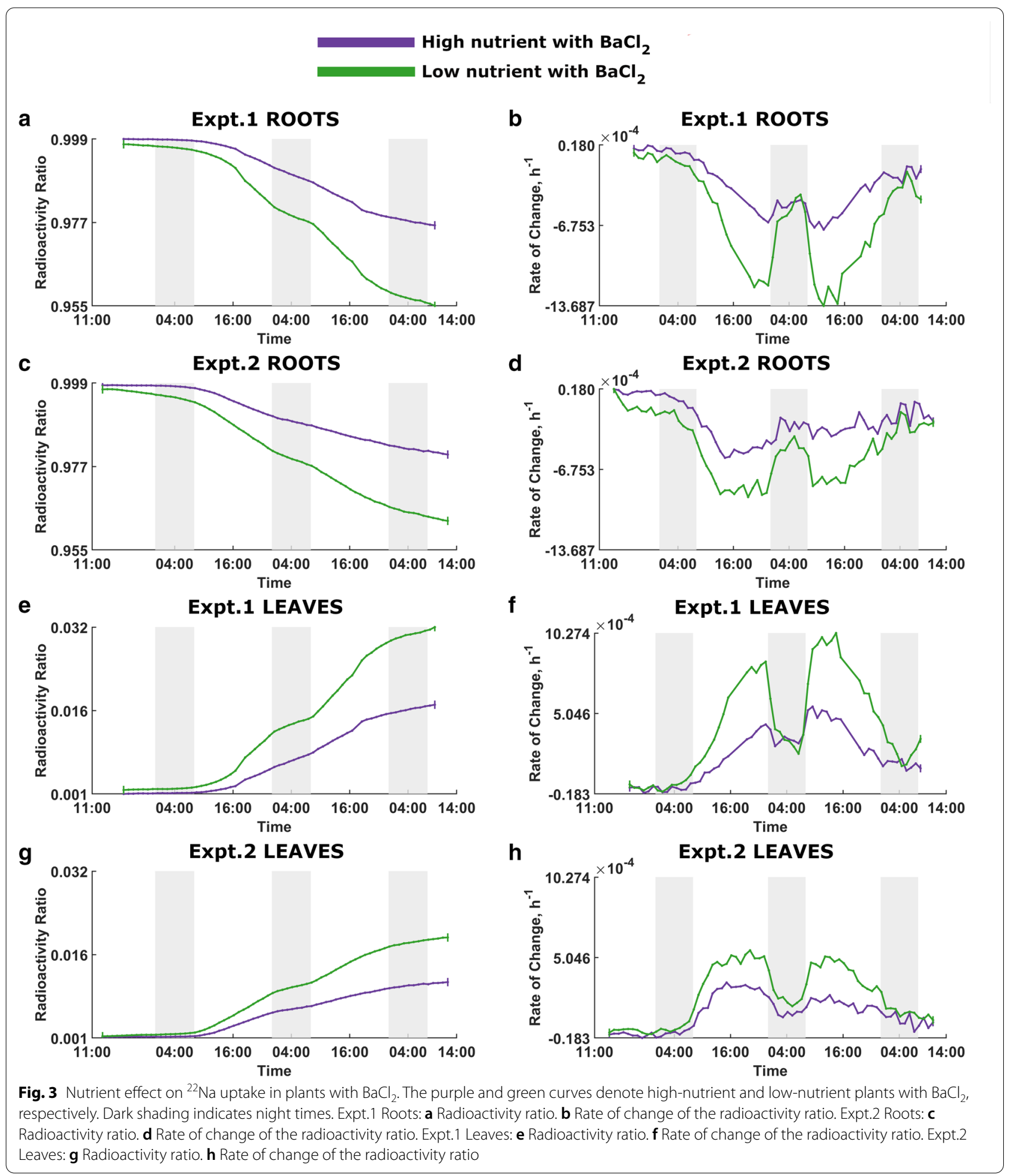

\section{Discussion}

In this study, we analysed sodium influx dynamics in barley plants using a clinical PET/CT scanner. Past studies on plants have primarily been carried out on specialised plant PET scanners or small animal PET scanners, with the exception of Karve et al. [31]. Plant or small animal PET scanners have small fieldsof-view, which limit the number of plants that can be 


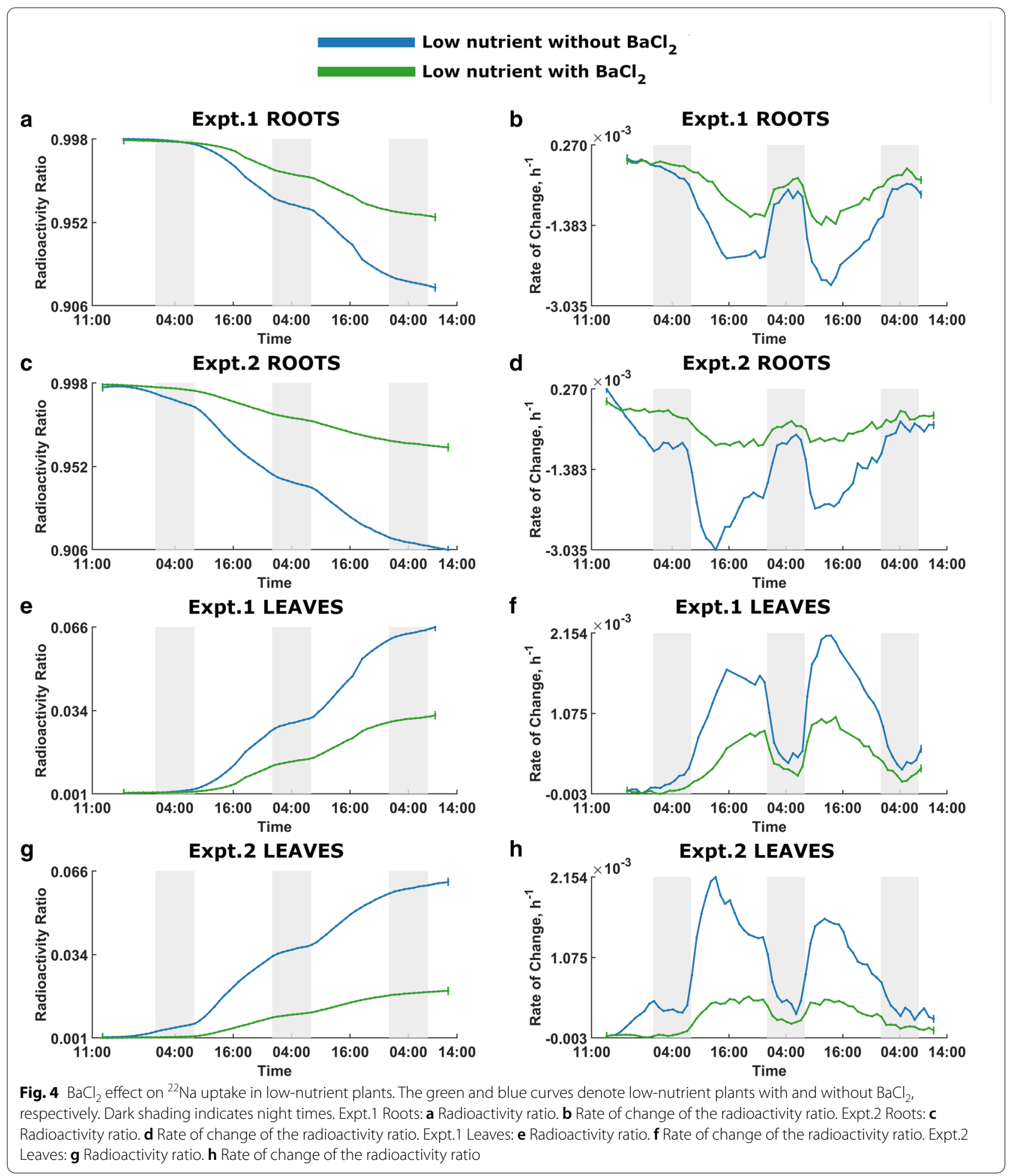

simultaneously scanned, and the size of the plants. In contrast, clinical PET scanners have larger FOVs and controllable bed positioning are advantageous for scanning full-sized plants and multiple plants at once, as in the four scanned simultaneously in the current experiments. This demonstrates the potential for clinical PET systems in high-throughput phenotyping of ion transport, furthermore critical as salinity transport and 


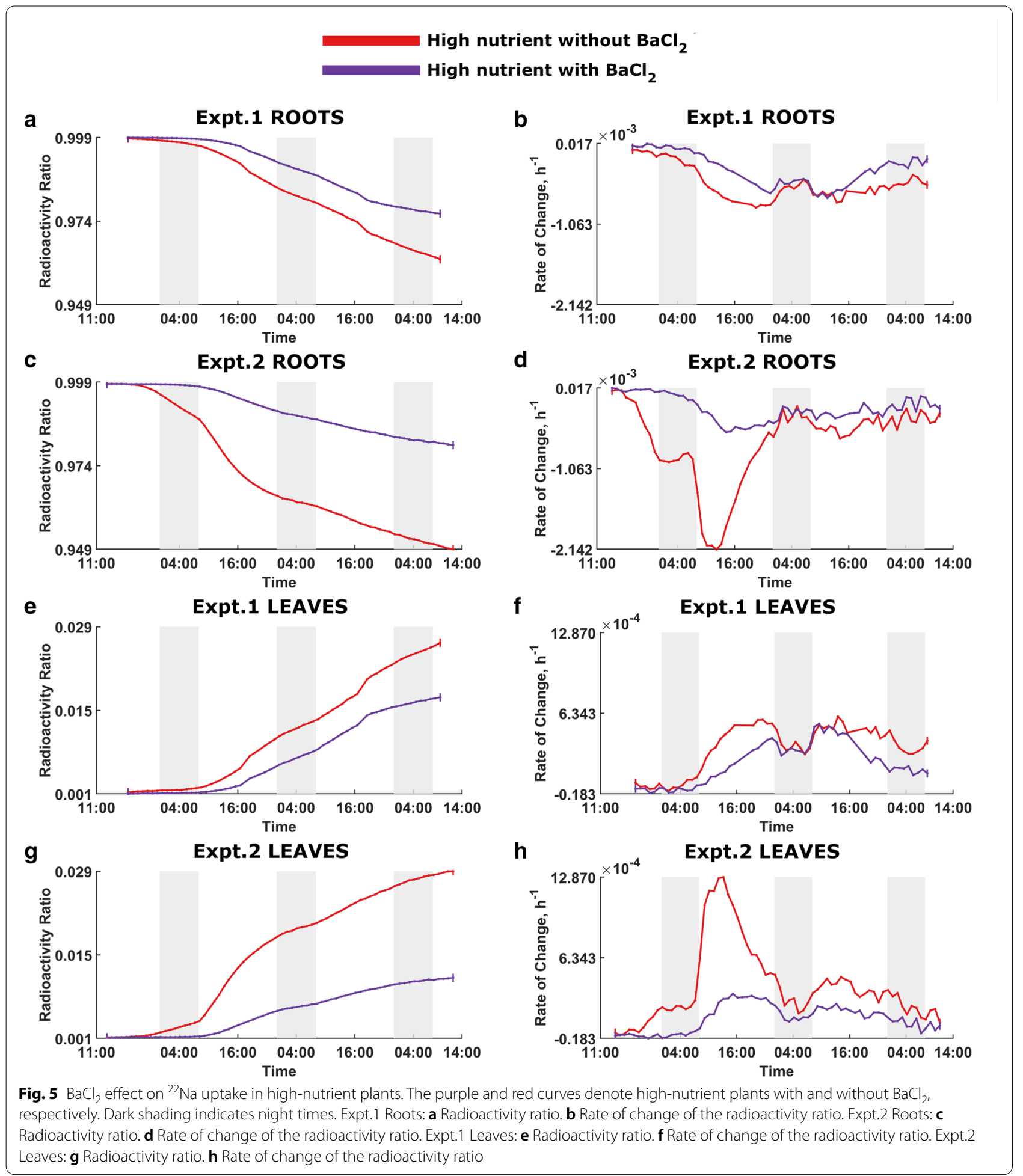

tolerance traits can be uniquely expressed at different developmental stages in crop plants [34, 35].

Moreover, dedicated plant PET scanners are not accessible to most plant research groups, while clinical PET scanners exist in many research institutions. Clinical PET scanners provide high-level correction methods in image reconstruction to maximise the radioactivity quantification accuracy, higher spatial resolution and 
Table 1 Comparison of estimated total PET radioactivity with and without CT-based Attenuation Correction with the ground truth radioactivity values in Experiment 1

\begin{tabular}{lllll}
\hline & $\begin{array}{l}\text { High nutrient } \\
\text { without inhibitor radioactivity } \\
\text { (MBq) }\end{array}$ & $\begin{array}{l}\text { High nutrient with inhibitor } \\
\text { radioactivity (MBq) }\end{array}$ & $\begin{array}{l}\text { Low nutrient without inhibitor } \\
\text { radioactivity (MBq) }\end{array}$ & $\begin{array}{l}\text { Low nutrient } \\
\text { with inhibitor } \\
\text { radioactivity (MBq) }\end{array}$ \\
\hline $\begin{array}{l}\text { Ground truth } \\
\text { Estimated with CT }\end{array}$ & 1.74 & 1.79 & 1.69 & 1.70 \\
$\begin{array}{l}\text { Attenuation Cor- } \\
\text { rection }\end{array}$ & 1.88 & 1.78 & 1.78 \\
$\begin{array}{l}\text { Estimated without } \\
\text { CT Attenuation }\end{array}$ & 0.81 & 0.72 & & 0.72 \\
Correction & & & & 0.76 \\
\hline
\end{tabular}

Note that radioactivity values include the beaker and solution in which the plants are situated during the experiments

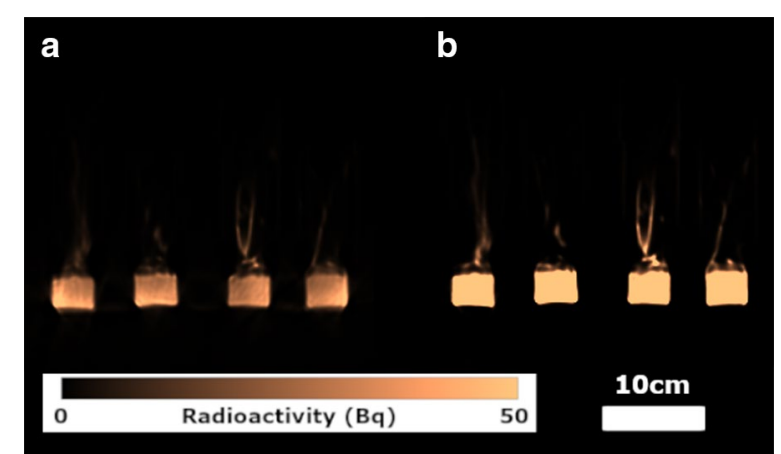

Fig. 6 Comparison of PET images reconstructed a without and b with CT-based Attenuation Correction. The images without correction contain significant inaccuracies in the voxel localized radioactivity measures

higher sensitivity, which are all advantageous in the accurate quantification of ion distribution in plants. As demonstrated by the estimation of total radioactivity (Table 1) and voxelwise localised intensities (Fig. 6), CTbased Attenuation Correction, a crucial element of every in vivo PET scan, is equally important in plant imaging for obtaining accurate radioactivity estimates. The use of CT imaging in plant studies has prompted studies on the effects of radiation exposure [36, 37]. It is important to distinguish between clinical (human) PET/CT systems, and $\mu \mathrm{CT}$ systems. Experiments such as the ones we report on clinical PET/CT scanners provide approximately the same radiation exposure as plants would absorb in 1-2 days of background radiation outdoors. The exposure from $\mu \mathrm{CT}$ systems, in contrast, is 6-7 orders of magnitude higher.

In previous studies, PET images or plant setup photographs, co-registered with PET images were used to acquire the plant's structural information to mark ROIs for analysis. Due to thin tissues in plants, plant PET images are more susceptible to partial volume effects and it is challenging to mark ROIs on these images [38].
We exploited the CT component of the clinical PET/CT scanner to mark ROIs on PET images. Therefore, beyond the superior attenuation correction using a PET/CT system, they are advantageous in delineating small plant structures for ROI analyses.

In this study, we included a low-nutrient treatment as well as a cation channel inhibitor treatment $\left(\mathrm{BaCl}_{2}\right)$ to directly test the sensitivity of the PET system, i.e. its ability to detect subtle differences between sodium transport rates within the same background plant species. Lownutrient growth solutions have been shown to upregulate sodium transport in rice, the hypothesis being that nutrient deprivation, particularly of potassium, causes the plant to use similar ions, like sodium, to replace cellular roles $[39,40]$. Similarly, inclusion of sodium channel blockers, such as $\mathrm{BaCl}_{2}$, have been shown to have marked effects on decreasing sodium uptake in previous radiotracer experiments [16, 41-43]. In the experiments we report on herein, the differences created by the inhibitor and low nutrient treatments were accurately and reliably detected, indicating this system will have application in measuring subtle differences in sodium transport between treatments or genetic mutants.

The diurnal pattern of ${ }^{22} \mathrm{Na}$ transport is an effect that has not previously been described experimentally, however has been hypothesized recently [44-46]. Future work is required to determine whether this fundamental sodium transport characteristic has important implications for how plants survive under conditions of elevated soil sodium conditions.

\section{Conclusion}

The utility of clinical PET for multi-day continuous imaging of sodium transport in plants has been demonstrated using a ${ }^{22} \mathrm{Na}$ tracer in barley plants, with four cases of varied nutrient and inhibitor levels imaged simultaneously. This technique provides a way to observe, in real time, genetic and treatment effects on sodium transport 
in plants, which will likely prove useful in the study of mutants lacking genes coding for various aspects of sodium transport at cellular and whole-plant levels.

\section{Methods}

Plants were scanned continuously in a clinical PET/CT scanner (Siemens Biograph128 mCT), incorporating two diurnal and nocturnal periods, running for $65 \mathrm{~h}$ (Experiment 1) and $72 \mathrm{~h}$ (Experiment 2), respectively, for influx analysis.

\section{Plant material and growth conditions}

Barley (Hordeum vulgare L. spp. vulgare-cultivar Bass) seeds were grown in a growth chamber (Conviron) at day/night conditions of $20{ }^{\circ} \mathrm{C} / 15{ }^{\circ} \mathrm{C}, 12 \mathrm{~h} / 8 \mathrm{~h}$ with a constant relative humidity of $60 \%$, and a light intensity of $200 \mu \mathrm{mol} / \mathrm{m}^{2} / \mathrm{s}$ at plant height. Eight seeds per mesh collar were surface-sterilised in $1 \%(\mathrm{v} / \mathrm{v})$ sodium hypochlorite for $15 \mathrm{~min}$ and washed four times with reverse-osmosis (RO) water for $15 \mathrm{~min}$. Seeds were germinated in acid-washed sand for 3 days prior to transfer to 14-L hydroponic systems containing modified Johnson's solution: solutions contained $0.5 \mathrm{mM} \mathrm{Ca}\left(\mathrm{NO}_{3}\right)_{2}$, $0.5 \mathrm{mM} \mathrm{KH}_{2} \mathrm{PO}_{4}, 0.25 \mathrm{mM} \mathrm{MgSO}, 0.25 \mathrm{mM} \mathrm{K}_{2} \mathrm{SO}_{4}$, $6.25 \mu \mathrm{M} \mathrm{H}_{3} \mathrm{BO}_{3}, 20 \mu \mathrm{M}$ FeEDTA, $0.5 \mu \mathrm{M} \mathrm{ZnSO}_{4}, 0.5 \mu \mathrm{M}$ $\mathrm{MnSO}_{4}, 0.125 \mu \mathrm{M} \mathrm{CuSO}$, and $0.125 \mu \mathrm{M} \mathrm{Na} \mathrm{MoO}_{4}$ (pH adjusted to 6.3 to 6.35 , using $1 \mathrm{M} \mathrm{KOH}$ ). A total of $0.02 \mathrm{mM} \mathrm{N}$ was available in EDTA. Nutrient solutions were completely exchanged every 2 days to ensure depletion of nutrients did not exceed 15\% of target concentrations.

At 9 days post germination, $50 \%$ of plants were switched to a 'low nutrient' solution (containing only $0.2 \mathrm{mM} \mathrm{CaSO}_{4}, \mathrm{pH}$ adjusted to 6.3 to 6.35 using $1 \mathrm{M}$ $\left.\mathrm{Ca}(\mathrm{OH})_{2}\right)$ from the 'high nutrient' solution described above. At 11 days post germination, the plants were carefully moved, in nutrient solution systems, to the PET scanning facility for analysis.

\section{Plant preparation and scanning procedure}

Eight barley seedlings, affixed to 'collars', were placed in 150-mL beakers, two collars from each of the 'high-nutrient' and 'low-nutrient' hydroponic tanks. A cation-channel inhibitor, $\mathrm{BaCl}_{2}$, was added to one 'low-nutrient' and one 'high-nutrient' beaker, thereby creating four unique plant/nutrient solution combinations. Two beakers were placed in each of two larger plastic containers, maintaining equal distance between adjacent pairs. Each beaker was encircled by a PERSPEX ${ }^{\mathrm{R}}$ cylinder to maintain radioactive isolation for each plant. A reference source with known activity was placed in a separate tube to check whether there was any drift in the scanner during the experiment. The containers were placed in the centre of the PET scanner field-of-view (Fig. 7).

The total quantity of ${ }^{22} \mathrm{Na}$ was added to $12 \mathrm{~mL}$ of $\mathrm{RO}$ water and mixed thoroughly. Immediately prior to initiation of PET data collection, $3 \mathrm{~mL}$ of the ${ }^{22} \mathrm{Na}$ radiotracer was administered into the solution in each beaker using a syringe with a $10-\mathrm{cm}$ needle to completely mix the solutions and divide the total radioactivity as evenly as possible between the beakers (Table 2).

In each experiment, $\mathrm{CT}$ images of the arrangement were acquired both at the beginning and at the end of the experiment with $120 \mathrm{kV}$ tube voltage, and $313 \mathrm{~mA}$ and $243 \mathrm{~mA}$ tube currents in Experiments 1 and 2, respectively. The CT images were used in PET attenuation correction and for defining ROIs in the plants (see below). Following the initial CT scan, plants were imaged continuously in the PET detector ring with times as detailed in Table 2. Plants were illuminated by a white fluorescent

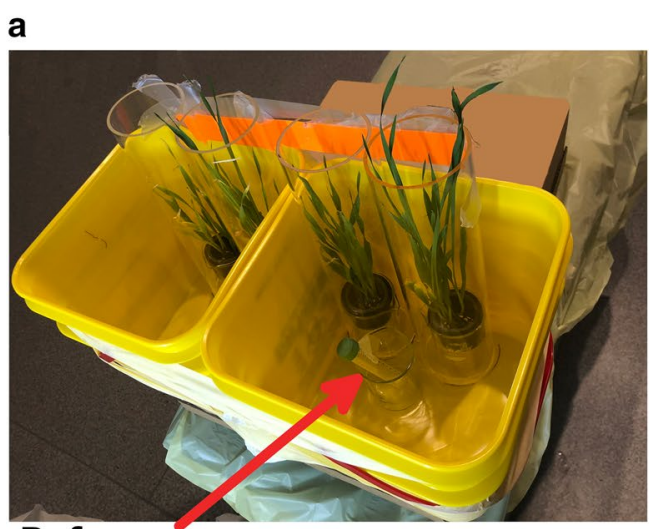

Reference source

b

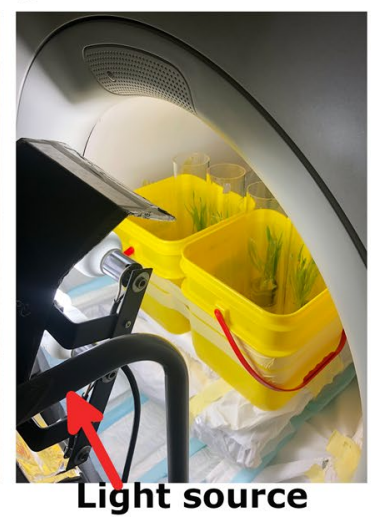

c

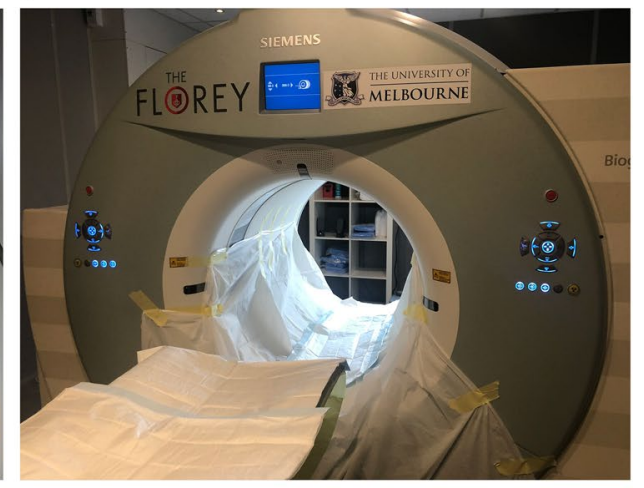

Fig. 7 Experimental setup. a Four plant setups in two larger containers with the reference source, b Experimental setup in the scanner with the light source on, c Siemens Biograph128 mCT PET/CT scanner 
Table 2 Radioactivity levels and scan times

\begin{tabular}{llllll}
\hline & $\begin{array}{l}\text { High nutrient } \\
\text { without } \mathrm{BaCl}_{\mathbf{2}} \\
\text { radioactivity (MBq) }\end{array}$ & $\begin{array}{l}\text { High nutrient } \\
\text { with } \mathrm{BaCl}_{\mathbf{2}} \\
\text { radioactivity } \mathbf{( M B q )}\end{array}$ & $\begin{array}{l}\text { Low nutrient } \\
\text { without } \mathrm{BaCl}_{\mathbf{2}} \\
\text { radioactivity (MBq) }\end{array}$ & $\begin{array}{l}\text { Low nutrient } \\
\text { with } \mathrm{BaCl}_{\mathbf{2}} \\
\text { radioactivity (MBq) }\end{array}$ \\
\hline Experiment 1 & 1.74 & 1.79 & 1.69 & 1.70 \\
Experiment 2 & 2.25 & 2.09 & 2.00 & 2.03 & 65 \\
times (hours)
\end{tabular}

light source with an intensity of $200 \mu \mathrm{mol} / \mathrm{m}^{2} / \mathrm{s}$ at plant height on a timer to provide the same $12 \mathrm{~h}$ day $/ 8 \mathrm{~h}$ night light cycle to which the plants were originally entrained in the growth chambers.

\section{Image reconstruction}

PET images were reconstructed on the Siemens scanner. Dynamic image sequences were reconstructed for each experiment, in 1-h intervals with 109 axial slices per time point, using the Point Spread Function/Time of Flight method with $1.59 \mathrm{~mm} \times 1.59 \mathrm{~mm}$ in-plane voxel size, $2.027 \mathrm{~mm}$ slice thickness, scatter and decay corrections applied, in addition to attenuation correction using the CT images.

\section{Quantitative image analysis}

The reconstructed PET images were analysed using MATLAB (Version R2019a) and ROIs in the CT images were delineated using the Athena DICOM viewer.

As it was challenging to distinguish each plant's anatomical boundaries precisely in the PET images, the boundaries, including roots, stem, and leaves, were identified in CT images. Across the experimental interval,

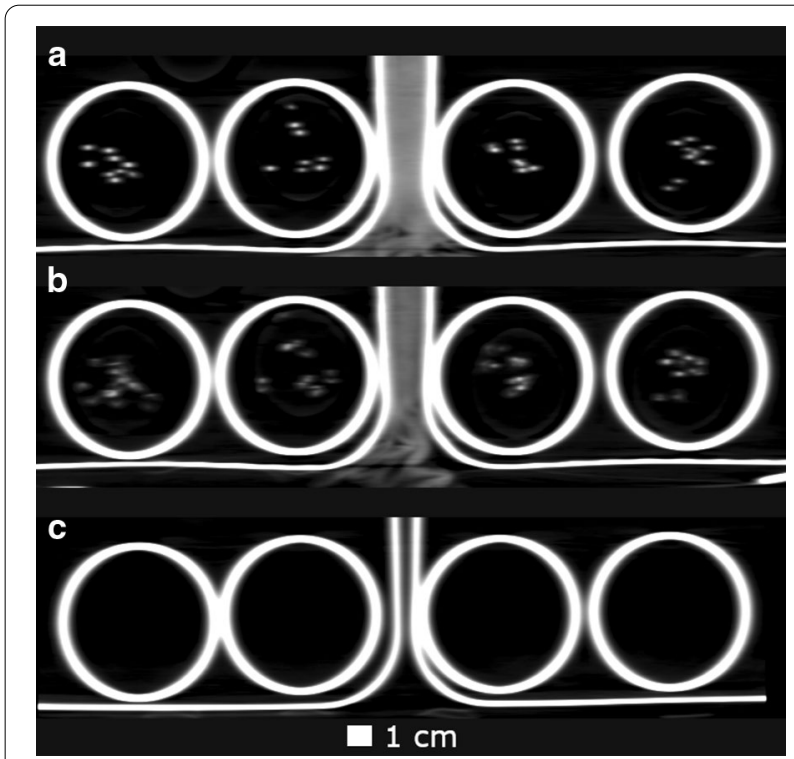

Fig. 8 Coronal plane CT slices through a stems, b leaves, and $\mathbf{c}$ a plane above the level of leaves. Voxel size is $0.98 \mathrm{~mm} \times 0.98 \mathrm{~mm}$ the stems of the plants did not grow significantly, and the leaves grew marginally. Therefore, the CT images from the end of the experiment were used to notate heights of each region in the coronal plane. Figure 8 shows three different CT coronal plane slices in Experiment 2. The bottoms of the beakers were used as a reference and CT heights were converted to PET image space using voxel dimensions. The vertical boundaries of the PERSPEX ${ }^{\mathrm{R}}$ cylinders were considered to be the vertical boundaries of each of the plants. 3D ROIs marked on PET images using this method are shown in Fig. 9a, b, with the PET images overlaid on CT in Fig. 9c. These projection images were generated by summing voxel values across slices (through-plane direction).

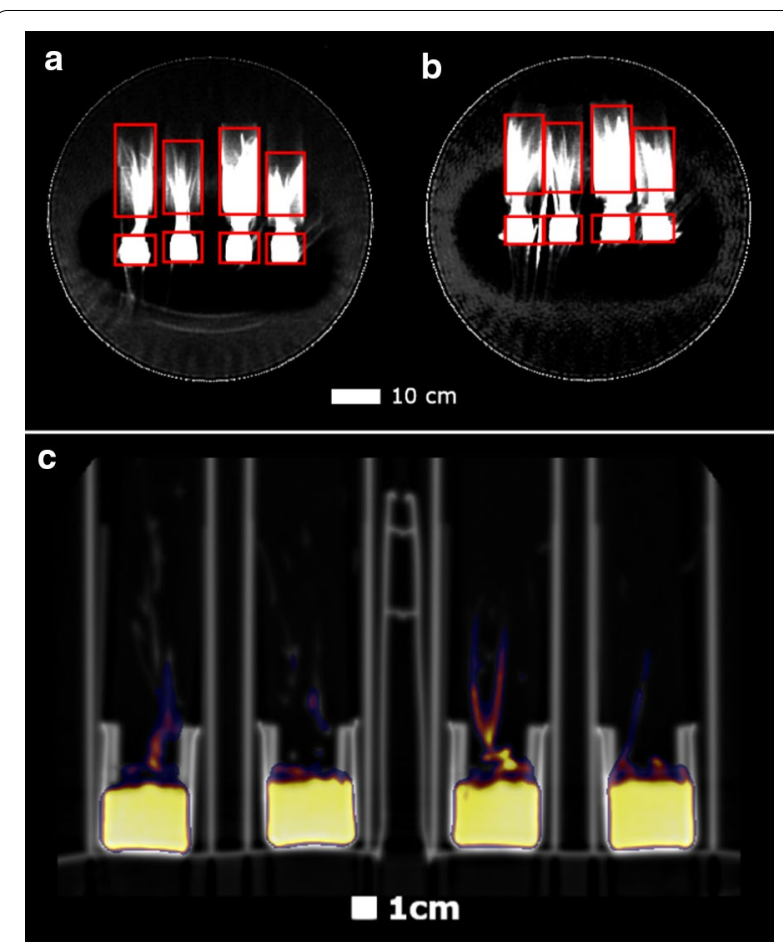

Fig. 9 High contrast PET projection images with Regions of Interest overlaid (red boxes) for $\mathbf{a}$ Experiment 1, and $\mathbf{b}$ Experiment 2. Projections are given by the summation of all voxel intensities in the through-plane direction. The $\mathrm{ROIs}$ are $3 \mathrm{D}$ rectangular prisms, with identical spatial extent in the through-plane direction. c Axial PET image overlaid on CT image 
At each time point, radioactivity in each ROI was calculated by summing across the ROI's voxels. To compare radioactivity between regions, values were normalized at each time point using the relevant plant's total radioactivity, calculated at each time point. Rate of change of radioactivity over time was calculated using first central differences.

\section{Supplementary Information}

The online version contains supplementary material available at https://doi. org/10.1186/s13007-021-00707-8.

Additional file 1: Movie Exp 1. Time-lapse video of ${ }^{22} \mathrm{Na}$ dynamics for Experiment 1.

Additional file 2: Movie Exp 2. Time-lapse video of ${ }^{22} \mathrm{Na}$ dynamics for Experiment 2.

\section{Abbreviations}

PET: Positron emission tomography; CT: Computed tomography; MRI: Magnetic resonance imaging; RO: Reverse osmosis; EDTA: Ethylenediamine tetraacetic acid; ROI: Region of interest; DICOM: Digital imaging and communications in medicine; FOV: Field-of-view.

\section{Acknowledgements}

The authors acknowledge the facilities and scientific and technical assistance of the National Imaging Facility, a National Collaborative Research Infrastructure Strategy (NCRIS) capability, at the Melbourne Brain Centre Imaging Unit, the University of Melbourne. This project was supported by the Melbourne Brain Centre Imaging Unit and the first author would also like to acknowledge the Rowden White scholarship for its assistance in his research.

\section{Authors' contributions}

DCP and RCW designed the experiments and DCP, RCW and GPR performed the experiments. GPR analysed the dataset and DCP, GPR, RCW, CED and LAJ contributed in interpreting the results. GPR and DCP wrote the manuscript and all authors contributed to the revision of the manuscript. All authors read and approved the final manuscript.

\section{Funding}

This research is supported by a Melbourne School of Engineering grant (LAJ).

\section{Availability of data and materials}

The datasets used and/or analysed during the current study are available from the corresponding author on reasonable request.

\section{Ethics approval and consent to participate}

Not applicable.

\section{Consent of publication \\ Not applicable.}

\section{Competing interests}

The authors declare that they have no competing interests.

\section{Author details}

${ }^{1}$ Melbourne Brain Centre Imaging Unit, The University of Melbourne, Melbourne, VIC, Australia. ${ }^{2}$ Department of Biomedical Engineering, The University of Melbourne, Melbourne, VIC, Australia. ${ }^{3}$ Australian Plant Phenomics Facility, The Plant Accelerator, School of Agriculture, Food \& Wine, University of Adelaide, Urrbrae, SA, Australia. ${ }^{4}$ Faculty of Veterinary and Agriculture Sciences, School of Agriculture and Food, The University of Melbourne, Melbourne, VIC, Australia. ${ }^{5}$ Faculty of Land and Food Systems, University of British Columbia, Vancouver, BC V6T 1Z4, Canada.

Received: 28 April 2020 Accepted: 4 January 2021

Published online: 19 January 2021

\section{References}

1. Britto DT, Siddiqi MY, Glass ADM, Kronzucker HJ. Futile transmembrane $\mathrm{NH} 4+$ cycling: a cellular hypothesis to explain ammonium toxicity in plants. Proc Natl Acad Sci USA. 2001;98(7):4255-8. https://doi. org/10.1073/pnas.061034698.

2. Converse AK, Ahlers EO, Bryan TW, Hetue JD, Lake KA, Ellison PA, Engle JW Barnhart TE, Nickles RJ, Williams PH, DeJesus OT. Mathematical modeling of positron emission tomography (PET) data to assess radiofluoride transport in living plants following petiolar administration. Plant Methods. 2015;11(1):1-7. https://doi.org/10.1186/s13007-015-0061-y.

3. Kronzucker HJ, Siddiqi MY, Glass ADM. Conifer root discrimination against soil nitrate and the ecology of forest succession. Nature. 1997;385(6611):59-61. https://doi.org/10.1038/385059a0.

4. Minchin PEH, Thorpe MR. Using the short-lived isotope $11 \mathrm{C}$ in mechanistic studies of photosynthate transport. Funct Plant Biol. 2003;30(8):83141. https://doi.org/10.1071/FP03008.

5. Kiser MR, Reid CD, Crowell AS, Phillips RP, Howell CR. Exploring the transport of plant metabolites using positron emitting radiotracers. HFSP J. 2008;2(4):189-204. https://doi.org/10.2976/1.2921207.

6. Ruben S, Hassid WZ, Kamen MD. Radioactive carbon in the study of photosynthesis. J Am Chem Soc. 1939;61(3):661-3. https://doi.org/10.1021/ ja01872a034.

7. Mcnaughton GS, Presland MR. Whole plant studies using radioactive 13-nitrogen: I. Techniques for measuring the uptake and transport of nitrate and ammonium ions inhydroponically grown zea mays. J Exp Bot. 1983;34(7):880-92. https://doi.org/10.1093/jxb/34.7.880.

8. Ritchie RJ. Estimation of cytoplasmic nitrate and its electrochemical potential in barley roots using 13NO3-and compartmental analysis. New Phytol. 2006;171(3):643-55. https://doi.org/10.111 1/j.1469-8137.2006.01768.x.

9. Kronzucker HJ, Britto DT. Sodium transport in plants: a critical review. New Phytol. 2011;189(1):54-81. https://doi.org/10.111 1/j.1469-8137.2010.03540.x.

10. Plett DC, Møller IS. Na+ transport in glycophytic plants: what we know and would like to know. Plant Cell Environ. 2010;33(4):612-26. https://doi. org/10.1111/j.1365-3040.2009.02086.x

11. Davenport R, James RA, Zakrisson-plogander A, Tester M, Munns R. Control of sodium transport in Durum wheat. Plant Physiol. 2017;137(November):807-18. https://doi.org/10.1104/pp.104.057307.accumulation.

12. Davenport RJ, Reid RJ, Smith FA. Sodium-calcium interactions in two wheat species differing in salinity tolerance. Physiol Plant. 1997;99(2):3237. https://doi.org/10.1034/j.1399-3054.1997.990216x.

13. Krysan PJ, Young JC, Sussman MR, Krysan PJ, Young JC, Sussman MR. Sodium influx and accumulation in arabidopsis. Plant Physiol. 2017;11(12):2283-90. https://doi.org/10.1104/pp.103.022178.Soil.

14. Flam-Shepherd R, Huynh WQ, Coskun D, Hamam AM, Britto DT, Kronzucker HJ. Membrane fluxes, bypass flows, and sodium stress in rice: the influence of silicon. J Exp Bot. 2018;69(7):1679-92. https://doi. org/10.1093/jxb/erx460.

15. Hamam AM, Britto DT, Flam-Shepherd R, Kronzucker HJ. Measurement of differential $\mathrm{Na}+$ effulx from apical and bulk root zones of intact barley and Arabidopsis plants. Front Plant Sci. 2016;7(MAR2016):1-8. https://doi. org/10.3389/fpls.2016.00272.

16. Schulze LM, Britto DT, Li M, Kronzucker HJ. A pharmacological analysis of high-affinity sodium transport in barley (Hordeumvulgare L.): a 24Na+/42K+ study. J Exp Bot. 2012;63(7):2479-89. https://doi. org/10.1093/jxb/err419.

17. Nevo E, Gorham J, Beiles A. Variation for $11 \mathrm{Na}$ uptake in wild emmer wheat, Triticum dicoccoides in Israel: salt tolerance resources for wheat improvement. J Exp Bot. 1992;43(4):511-8. https://doi.org/10.1093/ jxb/43.4.511.

18. Smitharani JA, Sowmyashree ML, Vasantha KM, Srivastava M, Sashidhar VR. 22Na influx is significantly lower in salt tolerant groundnut (Arachis hypogaea) varieties. Physiol Mol Biol Plants. 2014;20(1):49-55. https://doi. org/10.1007/s12298-013-0202-6.

19. Li L, Zhang Q, Huang D. A review of imaging techniques for plant phenotyping. Sensors (Switzerland). 2014;14(11):20078-111. https://doi. org/10.3390/s141120078.

20. de Vylder J, Vandenbussche F, Hu Y, Philips W, van der Straeten D. Rosette Tracker: an open source image analysis tool for automatic quantification 
of genotype effects. Plant Physiol. 2012;160(3):1149-59. https://doi. org/10.1104/pp.112.202762.

21. Zia S, Romano G, Spreer W, Sanchez C, Cairns J, Araus JL, Müller J. Infrared thermal imaging as a rapid tool for identifying water-stress tolerant maize genotypes of different phenology. J Agron Crop Sci. 2013;199(2):75-84. https://doi.org/10.1111/j.1439-037X.2012.00537.X.

22. Windt CW, Vergeldt FJ, De Jager PA, Van As H. MRI of long-distance water transport: a comparison of the phloem and xylem flow characteristics and dynamics in poplar, castor bean, tomato and tobacco. Plant Cell Environ. 2006;29(9):1715-29. https://doi.org/10.1111/j.1365-3040.2006.01544 $x$

23. Perret JS, Al-Belushi ME, Deadman M. Non-destructive visualization and quantification of roots using computed tomography. Soil Biol Biochem. 2007;39(2):391-9. https://doi.org/10.1016/j.soilbio.2006.07.018.

24. McKay RML, Palmer GR, Ma XP, Layzell DB, McKee BTA. The use of positron emission tomography for studies of long-distance transport in plants: uptake and transport of 18F. Plant Cell Environ. 1988;11(9):851-61. https ://doi.org/10.1111/j.1365-3040.1988.tb01911.x.

25. Partelová D, Uhrovčík J, Lesný J, Horník M, Rajec P, Kováč P, Hostin S. Application of positron emission tomography and 2-[18F]fluoro-2-deoxyD-glucose for visualization and quantification of solute transport in plant tissues. Chem Pap. 2014;68(11):1463-73. https://doi.org/10.2478/s1169 6-014-0609-8

26. De Schepper V, Bühler J, Thorpe M, Roeb G, Huber G, van Dusschoten D, Jahnke S, Steppe K. 11C-PET imaging reveals transport dynamics and sectorial plasticity of oak phloem after girdling. Front Plant Sci. 2013:4(JUN):1-9. https://doi.org/10.3389/fpls.2013.00200

27. Thorpe MR, Ferrieri AP, Herth MM, Ferrieri RA. 11C-imaging: methyl jasmonate moves in both phloem and xylem, promotes transport of jasmonate, and of photoassimilate even after proton transport is decoupled. Planta. 2007:226(2):541-51. https://doi.org/10.1007/s00425-007-0503-5.

28. Beer S, Streun M, Hombach T, Buehler J, Jahnke S, Khodaverdi M, Larue H, Minwuyelet S, Parl C, Roeb G, Schurr U, Ziemons K. Design and initial performance of PlanTIS: a high-resolution positron emission tomograph for plants. Phys Med Biol. 2010;55(3):635-46. https://doi. org/10.1088/0031-9155/55/3/006.

29. Jahnke S, Menzel MI, Van Dusschoten D, Roeb GW, Bühler J, Minwuyelet S, Blümler P, Temperton VM, Hombach T, Streun M, Beer S, Khodaverdi M, Ziemons K, Coenen HH, Schurr U. Combined MRI-PET dissects dynamic changes in plant structures and functions. Plant J. 2009;59(4):634-44. https://doi.org/10.1111/j.1365-313X.2009.03888.x.

30. Streun M, Beer S, Daemen J, Dorscheid R, Erven A, Jokhovets L, Meessen L, Mekala NB, Mulhens O, Noldgen H, Pap M, Peters C, Ramm M, Reinartz S, Scheins J, Schramm N, Zwaans B, Kemmerling G, Hamisch Y, et al. PhenoPET: A dedicated PET scanner for plant research based on digital SiPMs (DPCs). In: 2014 IEEE nuclear science symposium and medical imaging conference, NSS/MIC 2014. 2016. pp. 2-4. https://doi.org/10.1109/NSSMI C.2014.7430860.

31. Karve AA, Alexoff D, Kim D, Schueller MJ, Ferrieri RA, Babst BA. In vivo quantitative imaging of photoassimilate transport dynamics and allocation in large plants using a commercial positron emission tomography (PET) scanner. BMC Plant Biol. 2015;15(1):1-11. https://doi.org/10.1186/ s12870-015-0658-3.

32. Fujimaki S, Maruyama T, Suzui N, Kawachi N, Miwa E, Higuchi K. Base to tip and long-distance transport of sodium in the root of common reed [Phragmites australis (Cav.) Trin. ex Steud.] at steady state under constant high-salt conditions. Plant Cell Physiol. 2015;56(5):943-50. https://doi. org/10.1093/pcp/pcv021.

33. Ariño-Estrada G, Mitchell GS, Saha P, Arzani A, Cherry SR, Blumwald E, Kyme AZ. Imaging salt uptake dynamics in plants using PET. Sci Rep. 2019;9(1):18626. https://doi.org/10.1038/s41598-019-54781-z.
34. Mohammadi R, Mendioro MS, Diaz GQ, Gregorio GB, Singh RK. Genetic analysis of salt tolerance at seedling and reproductive stages in rice (Oryza sativa). Plant Breed. 2014;133(5):548-59. https://doi.org/10.1111/ pbr.12210.

35. Witzel K, Matros A, Strickert M, Kaspar S, Peukert M, Mühling KH, Börner A, Mock HP. Salinity stress in roots of contrasting barley genotypes reveals time-distinct and genotype-specific patterns for defined proteins. Mol Plant. 2014;7(2):336-55. https://doi.org/10.1093/mp/sst063.

36. Blaser SRGA, Schlüter S, Vetterlein D. How much is too much? -influence of X-ray dose on root growth of faba bean (Viciafaba) and barley (Hordeumvulgare). PLoS ONE. 2018;13(3):1-19. https://doi.org/10.1371/ journal.pone.0193669.

37. Zappala S, Helliwell JR, Tracy SR, Mairhofer S, Sturrock CJ, Pridmore T, Bennett M, Mooney SJ. Effects of X-ray dose on rhizosphere studies using x-ray computed tomography. PLoS ONE. 2013;8(6):e67250. https://doi. org/10.1371/journal.pone.0067250.

38. Alexoff DL, Dewey SL, Vaska P, Krishnamoorthy S, Ferrieri R, Schueller M, Schlyer DJ, Fowler JS. PET imaging of thin objects: measuring the effects of positron range and partial-volume averaging in the leaf of Nicotiana tabacum. Nucl Med Biol. 2011;38(2):191-200. https://doi.org/10.1016/j. nucmedbio.2010.08.004.

39. Hamam AM, Coskun D, Britto DT, Plett D, Kronzucker HJ. Plasmamembrane electrical responses to salt and osmotic gradients contradict radiotracer kinetics, and reveal $\mathrm{Na}+$-transport dynamics in rice (Oryzasativa L.). Planta. 2018;249(4):1037-51. https://doi.org/10.1007/s0042 5-018-3059-7.

40. Horie T, Costa A, Kim TH, Han MJ, Horie R, Leung HY, Miyao A, Hirochika H, An G, Schroeder Jl. Rice OsHKT2; 1 transporter mediates large Na+ influx component into K+-starved roots for growth. EMBO J. 2007;26(12):300314. https://doi.org/10.1038/sj.emboj.7601732.

41. Demidchik $V$, Tester M. Sodium fluxes through nonselective cation channels in the plasma membrane of protoplasts from Arabidopsis roots. Plant Physiol. 2002;128(2):379-87. https://doi.org/10.1104/pp.010524.

42. Kader MA, Lindberg S. Uptake of sodium in protoplasts of salt-sensitive and salt-tolerant cultivars of rice, Oryzasativa L. determined by the fluorescent dye SBFI. J Exp Bot. 2005;56(422):3149-58. https://doi. org/10.1093/jxb/eri312.

43. Volkov V, Amtmann A. Thellungiella halophila, a salt-tolerant relative of Arabidopsis thaliana, has specific root ion-channel features supporting $\mathrm{K}+/ \mathrm{Na}+$ homeostasis under salinity stress. Plant J. 2006;48(3):342-53. https://doi.org/10.1111/j.1365-313X.2006.02876.x.

44. Arsova B, Foster KJ, Shelden MC, Bramley H, Watt M. Dynamics in plant roots and shoots minimize stress, save energy and maintain water and nutrient uptake. New Phytol. 2020;225(3):1111-9. https://doi. org/10.1111/nph.15955.

45. Babla M, Cai S, Chen G, Tissue DT, Cazzonelli Cl, Chen ZH. Molecular evolution and interaction of membrane transport and photoreception in plants. Front Genet. 2019;10(October):1-17. https://doi.org/10.3389/ fgene.2019.00956.

46. Haydon MJ, Bell LI, Webb AAR. Interactions between plant circadian clocks and solute transport. J Exp Bot. 2011;62(7):2333-48. https://doi. org/10.1093/jxb/err040.

\section{Publisher's Note}

Springer Nature remains neutral with regard to jurisdictional claims in published maps and institutional affiliations. 